Jurnal Ilmiah Mahasiswa Kendali dan Listrik
Vol. 1, No. 1, June 2020, 23 - 32

\title{
RANCANG BANGUN SISTEM PENYIRAMAN TANAMAN SAYUR BERBASIS ARDUINO DENGAN SENSOR KELEMBABAN TANAH
}

\author{
Roy Harry Syidiq Pamungkas ${ }^{1}$, Sampurna Dadi Riskiono², Yudha Arya $\mathbf{P}^{3}$
}

Prodi S1 Teknik Komputer, Fakultas Teknik dan Ilmu Komputer, Universitas Teknokrat Indonesia Prodi S1 Teknik Elektro, Fakultas Teknik dan Ilmu Komputer, Universitas Teknokrat Indonesia

roypamungkas16@gmail.com, sampurna.go@teknokrat.ac.id, yudhaarya@gmail.com

\begin{abstract}
Development at this time is increasing, people expect a tool or technology that can help human work, so technology becomes a necessity for humans. This final task is made a device that can do the job of watering tomato plants automatically. This tool aims to replace the manual work becomes automatic. The benefit of this tool is that it can facilitate the work of humans in watering chili plants. This tool uses a soil moisture sensor which acts as a soil moisture detector and sends an order to Arduino Uno to turn on the relay driver so that the wiper motor can splash water according to the needs of the soil automatically. The making of this final project is done by designing, making and implementing system components which include Arduino uno as a controller, driver relay to blow on and off the wiper motor, LCD (Linquit Cristal Display) to display the percentage value of water content
\end{abstract}

Keywords: Arduino-Based, Vegetable, Watering System, Soil Moisture Sensor.

\begin{abstract}
Abstrak
Perkembangan pada zaman ini semakin meningkat, manusia mengharapkan sebuah alatatau teknologi yang dapat membantu pekerjaan manusia, sehinga teknologi menjadi kebutuhan bagi manusia. Tugas akhir ini dibuat sebua perangkat yang dapat melakukan pekerjaan menyiram tanaman tomat secara otomatis.Alat ini bertujuan untuk menggantikan pekerjaan manual menjadi otomatis. Manfaat yang didapat dari alat ini adalah dapat mempermudah pekerjaan manusia dalam menyiram tanaman cabai. Alat ini mengunakan sensor soil moisture /kelembaban tanah yang berfungsi sebagai pendeteksi kelembaban tanah dan mengirim perintah kepada Arduino uno guna menghidupkan driver relay agar motor wiper dapat menyiram air sesuai kebutuhan tanah secara otomatis. Pembuatan tugas akhir ini dilakukan dengan merancang, membuat dan mengimplementasikan komponen-komponen sistem yang meliputi Arduino unosebagai pengendali, driver relay untuk memghiupkan dan mematikan motor wiper, LCD (linquid Cristal Display) untuk menampilkan nilai presentase kadar air.
\end{abstract}

Kata Kunci: Arduino, Sayuran, Soil Moisture Sensor, Air Otomatis 



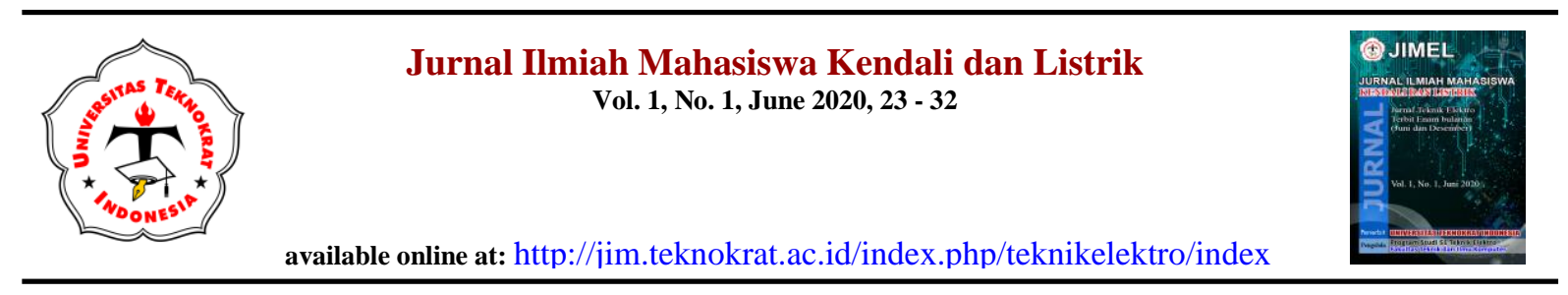

\section{PENDAHULUAN}

Saat ini kebutuhan akan tanaman tomat dan cabai semakin meningkat dikarenakan jumlah penduduk semakin meningkat dari tahun ketahun, banyak diantara manusia ingin bercocok tanam agar kebutuhan mereka terpenuhi, namun seringkali mereka tidak memiliki waktu untuk menyiram tanaman mereka dikarenakan mempunyai kesibukan yang tidak dapat ditinggalkan. Oleh karena itu pemanfaatan teknologi perlu dibuat agar dapat mempermudah mereka dalam menyiram tanaman, tanaman tomat sendiri membutuhkan kelembaban tertentu agar buah yang dihasilkan baik tanah yang digunakan untuk menanam tomat harus gembur/lembab dan tidak ada pasirnya.

Alat ini dibuat berfungsi untuk menyiram tanaman tomat dan cabai secara otomatis mengunakan sensor kelambaban tanah dan arduino uno. berdasarkan PH tanah yang sudah di set sesuai kebutuhan tanaman tomat dan cabai, alat ini juga dilengkapi LCD (Linquid Cristal Display) yang dapat menampilkan kondisi tanah apakah lembab atau kering sesuai dengan pembacaan dari sensor kelembaban tanah dalam bentuk nilai pada LCD. Alat ini juga dilengkapi dengan pompa Air guna penyiraman cabai,Alat ini sangat bermanfaat bagi manusia sekarang ini, karena dengan alat ini manusia tidak perlu lagi menyiram tanaman cabai secara manual setiap harinya, untuk itu alat ini bisa diaplikasikan pada manusia yang suka menanam cabai di dalam ruangan atau menanam cabai di kebun kecil di depan teras rumah dan di tempat lain nya yang besifat tertutup. Dengan latar belakang ini maka akan dirancangkan sebuah alat penyiram tanaman Cabai otomatis mengunakan sensor kelembaban tanah kemudian diproses oleh arduino uno dan di Instruksikan kepada LCD untuk menampilkan nilai kelembaban tanah sesuai dengan PH tanah.

\section{TELAAH PUSTAKA}

Berdasarkan pada penelitian-penelitian terdahulu beberapa penelitian terkait sensor suhu telah dilakukan antara lain sebuah penelitian penyiraman tanaman otomatis sudah pernah dilakukan, namun menggunakan sensor Lm35, sistem penyiraman tanaman yang telah dibuat dapat menyiram tanaman secara otomatis. Apabila suhu yang terdeteksi termasuk ke dalam kategori melebihi batas yang telah ditentukan, maka sistem dapat langsung bekerja menyiram tanaman secara otomatis [1]. Alat pendeteksi kekeruhan dan pemberi pakan ikan pada akuarium air tawar secara otomatis ini terdiri dari rangkaian sensor untuk mendeteksi kekeruhan ,dan minimum system dari mikrokontroler ATmega16 sebagai pusat kendali pada rangkaian sensor, dan rangkaian driver motor DC berfungsi sebagai mekanisme buka dan tutup box makanan [2]. pembuatan prototype pembersih wortel yang dikontrol oleh sebuah mikrokontroler arduino sebagai pengendali sistem dan sebuah motor penggerak. Pendeteksi dari kecerdasan alat ini ditambah sebuah sensor kekeruhan air [3]. Kelembaban tanah yang optimum untuk budidaya padi sawah dengan System of Rice Intensification(SRI) sangat penting dengan tujuan untuk meningkatkan produksi padi dan produktifitas air [4]. Sebuah sistem ke-lembaban tanah dan temperatur tanah mampu mempengaruhi nilai $\mathrm{pH}$ tanah di perkebunanjambu biji varietas kristal (Psidium guajavaL.).Sehingga dengan didapatkan nilai $\mathrm{pH}$ tanah tersebut mampu berpotensi mengindikasikan kandungan logam berat [5].

\section{TEORI DASAR}

\subsection{Mikrokontroler}

Mikrokontroler adalah sebuah sistem komputer fungsional dalam sebuah chip. Di dalamnya terkandung sebuah inti prosesor, memori (sejumlah kecil RAM, memori program, atau keduanya), dan perlengkapan input output.

Dengan kata lain, mikrokontroler adalah suatu alat elektronika digital yang mempunyai masukan dan keluaran serta kendali dengan program yang bisa ditulis dan dihapus dengan cara khusus, cara kerja mikrokontroler sebenarnya membaca dan menulis data. Mikrokontroler merupakan komputer didalam chip yang digunakan untuk mengontrol peralatan elektronik, yang menekankan efisiensi dan efektifitas biaya. Secara harfiahnya bisa disebut "pengendali kecil" dimana sebuah sistem elektronik yang sebelumnya banyak memerlukan komponen-komponen pendukung seperti IC TTL dan CMOS dapat direduksi/diperkecil dan akhirnya terpusat serta dikendalikan oleh mikrokontroler ini. 


\subsection{Arduino}

Arduino merupakan rangkaian elektronik yang bersifat open source, serta memiliki perangkat keras dan lunak yang mudah untuk digunakan. Arduino dapat mengenali lingkungan sekitarnya melalui berbagai jenis sensor dan dapat mengendalikan lampu, motor, dan berbagai jenis aktuator lainnya. Arduino mempunyai banyak jenis, di antaranya Arduino Uno, Arduino Mega 2560, Arduino Fio, dan lainnya [6].

\subsection{Sensor Soil Moisture/KelembabanTanah}

Sensor soil moisture yl-69 adalah sensor yang mampu mengukur kelembaban suatu tanah. Cara menggunakannya cukup mudah, yaitu membenamkan probe sensor ke dalam tanah dan kemudian sensor akan langsung membaca kondisi kelembaban tanah. Kelembaban tanah dapat diukur melalui value yang telah tersedia di dalam sensor, dibawah ini adalah ukuran kondisi tanah.

$$
\begin{aligned}
& 0-300=\text { Kering } \\
& 301-700=\text { Lembab } \\
& 701-1024=\text { Basah }
\end{aligned}
$$

Namun kekurangan dari sensor ini adalah sensor ini tidak dapat bekerja dengan baik di luar ruangan dikarenakan sensor ini rawan korosi atau karat. Versi baru dari sensor kelembaban tanah ini ialah probe sensornya sudah dilengkapi dengan lapisan kuning pelindung nikel. Sehingga nikel pada sensor kelembaban ini bisa terhindar dari oksidasi yang menyebabkan karat. Lapisan ini dinamakan Electroless nickel immersion gold (ENIG) dan lapisan ini memiliki beberapakeuntungan dibandingkan dengan lapisan permukaan konvensional seperti solder, seperti daya tahan oksidasi yang lebih bagus kadar air di dalam tanah.

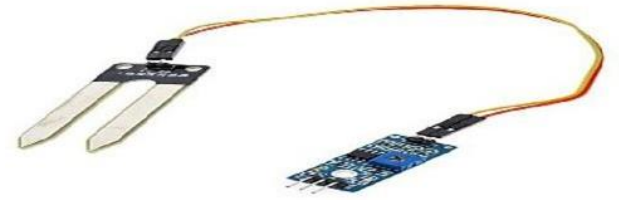

Gambar 1 Sensor Soil Moisture/Kelembaban Tanah

Sensor ini menggunakan dua buah probe untuk melewatkan arus melalui tanah lalumembaca tingkat resistansinya untuk mendapatkan tingkat kelembaban tanah. Makin banyak air membuat tanah makin mudah mengalirkan arus listrik (resistansi rendah), sementara tanah kering sulit mengalirkan arus listrik (resistansi tinggi). Ada tiga buah pin yang terdapat pada sensor ini yang mana masing masing pin memiliki tugas sendiri sendiri, yaitu : Analog output yang (kabel biru), Ground (kabel hitam), dan Power (kabelmerah).

Rumus Untuk mencari presentase kadar air :

$1024 * 100 / 1024=100$

Sensor Soil Moisture adalah sensor kelembaban tanah yang bekerja dengan prinsip membaca jumlah kadar air dalam tanah di sekitarnya. Sensor ini merupakan sensor ideal untuk memantau kadar air tanah untuk tanaman. Sensor ini menggunakan dua konduktor untuk melewatkan arus melalui tanah, kemudian membaca nilai resistansi untuk mendapatkan tingkat kelembaban. Lebih banyak air dalam tanah akan membuat tanah lebih mudah menghantarkan listrik (nilai resistansi lebih besar), sedangkan tanah kering akan mempersulit untuk menghantarkan listrik (nilai resistansi kurang). Sensor soil moisture dalam penerapannya membutuhkan daya sebesar $3.3 \mathrm{v}$ atau $5 \mathrm{~V}$ dengan keluaran tegangan sebesar $0-4.2 \mathrm{~V}$.

\subsection{Ilmu Tanah}

Dalam pertanian, tanah diartikan lebih khusus yaitu sebagai media tumbuhnya tanaman darat. tanah berasal dari hasil pelapukan batu bercampur dengan sisa-sisa bahan organik dan organisme (vegetasi atau hewan) yang hidup diatasnya atau di dalamnya. Selain itu di dalam tanah terdapat pula udara dan air.

Tanah tersusu dari empat bahan utama yaitu bahan mineral, bahan organik, air dan udara.Bahan - bahan penyusun tanah tersebut julmahnya masing - masing berbeda untuk setiap jenis tanah ataupun lapisan tanah. Pada tanah lapisan 
atas yang baik untuk pertumbuhan tanaman lahan kering (bukan sawah) umumnya mengandung $45 \%$ (volume) bahan mineral, 5\% bahan organik, $20-30 \%$ udara dan $20-30 \%$ air. Definisi serta hubungan - hubungan antara jumlah butir air dan udara dalam tanah. Percobaan Laboratorium untuk Berat Isi, Kadar Air dan Berat Jenis [7].

\subsection{Kadar Air}

Untuk menentukan kadar air sejumlah tanah ditempatkan dalam kurs (kaleng kecil) yang beratnya (W1) diketahui sebelumnya. Kurs dengan tanah ditimbang (W2) dan kemudian dimasukkan dalam oven yang temperaturnya 105oC untuk masa waktu 24 jam. Kemudian kurs tanah ditimbang kembali (W3). Dengan demikian berat air $=$ W2 - W3Berat tanah kering $=\mathrm{W} 3-\mathrm{W} 1$ Kadar air tanah $=(\mathrm{W} 2-\mathrm{W} 3) /(\mathrm{W} 3-\mathrm{W} 1)$

\subsection{Bertnam Tomat}

Tomat adalah tumbuhan dari family Solanaceae, yang berasal dari Amerika Tengah sampai Amerika Selatan dan termasuk dalam tanaman dengan hidup singkat. Untuk mecapai ketinggian 1-3 m, tanaman ini hanya memerlukan waktu sekitar $2-3$ bulan saja untuk melakukan panen. Selain itu, tanaman tomat termasuk dalam salah satu tanaman yang paling banyak dibutuhkan oleh masyarakat dan memiliki nilai ekonomis yang stabil.

Tomat adalah tanaman yang dapat tumbuh di berbagai tempat, dari dataran rendah sampai dataran tinggi. Agar dapat tumbuh dan berkembang dengan baik tanaman tomat membutuhkan tanah yang gembur, memiliki keasaman atau pH antara 5-6, memiliki sedikit kandungan air, dan banyak mengandung humus serta memiliki pengairan yang baik. Selain itu, tempat yang akan digunakan sebagai media tanam wajib memiliki curah hujan antara $100-220 \mathrm{~mm}$ per tahun [8].

\subsection{LCD Karakter 2x16/Display}

Display elektronik adalah salah satu komponen elektronika yang berfungsi sebagai tampilan suatu data, baik karakter, huruf ataupun grafik. LCD (Liquid Cristal Display) adalah salah satu jenis display elektronik yang dibuat dengan teknologi CMOS logic yang bekerja dengan tidak menghasilkan cahaya tetapi memantulkan cahaya yang ada di sekelilingnya terhadap front-lit atau mentransmisikan cahaya dari back-lit. LCD berfungsi sebagai penampil data baik dalam bentuk karakter, huruf, angka ataupun grafik.

LCD adalah lapisan dari campuran organik antara lapisan kaca bening dengan elektroda transparan indium oksida dalam bentuk tampilan seven-segment dan lapisan elektroda pada kaca belakang. Ketika elektroda diaktifkan dengan medan listrik (tegangan), molekul organik yang panjang dan silindris menyesuaikan diri dengan elektroda dari segmen. Lapisan sandwich memiliki polarizer cahaya vertikal depan dan polarizer cahaya horisontal belakang yang diikuti dengan lapisan reflektor. Cahaya yang dipantulkan tidak dapat melewati molekul-molekul yang telah menyesuaikan diri dan segmen yang diaktifkan terlihat menjadi gelap dan membentuk karakter data yang ingin ditampilkan.

\subsection{Motor Wiper}

Motor wiper dapat bergerak ketika motor wiper dialiri arus. Arus ini berasal dari baterai kemudian menuju ke fuse, lalu ke kunci kontak, lalu ke wiper switch dan kemudian ke motor wiper. Pada saat wiper dioperasikan kemudian dimatikan (off) maka lengan wiper harus kembali ke posisi semula (posisi bawah) jangan sampai berhenti ditengah-tengah yang nantinya dapat mengganggu pandangan pengendara. Sehingga diperlukan suatu sistem yang dapat membuat posisi wiper kembali ke posisi semula saat switch wiper di off kan.

\subsection{Power Supply De(Adaptor)}

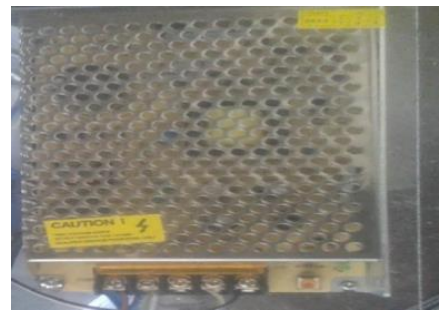

Gambar 2 Power Suplay DC

Prinsip Kerja DC Power Supply (Adaptor) adalah Arus Listrik yang kita gunakan di rumah, kantor dan pabrik pada umumnya adalah dibangkitkan, dikirim dan didistribusikan ke tempat masing-masing dalam bentuk Arus Bolak-balik atau arus AC (Alternating Current). Hal ini dikarenakan pembangkitan dan pendistribusian arus Listrik melalui bentuk arus bolak-balik (AC) merupakan cara yang paling ekonomis dibandingkan dalam bentuk arus searah atau arus DC 
(DirectCurrent). Akan tetapi, peralatan elektronika yang kita gunakan sekarang ini sebagian besar membutuhkan arus DC dengan tegangan yang lebih rendah untuk pengoperasiannya. Oleh karena itu, hampir setiap peralatan Elektronika memiliki sebuah rangkaian yangberfungsi untuk melakukan konversi arus listrik dari arus AC menjadi arus DC dan juga untuk menyediakan tegangan yang sesuai dengan rangkaian Elektronika-nya. Rangkaian yang mengubah arus listrik AC menjadi DC ini disebut dengan DC Power Supply atau dalam bahasa Indonesia disebut dengan Catu daya DC. DC Power Supply atau Catu Daya ini juga sering dikenal dengan nama "Adaptor".

Sebuah DC Power Supply atau Adaptor pada dasarnya memiliki 4 bagian utama agar dapat menghasilkan arus DC yang stabil. Ke empat bagian utama tersebut diantaranya adalah Transformer, Rectifier, Filter dan Voltage Regulator.

Sebelum kita membahas lebih lanjut mengenai Prinsip Kerja DC Power Supply, sebaiknya kita mengetahui Blok-blok dasar yang membentuk sebuah DC Power Supply atau Pencatu daya ini. Di bawah ini adalah Diagram Blok DC Power Supply (Adaptor) pada umumnya [9].

\section{METODE PENELITIAN}

\subsection{Alat dan Bahan}

\section{Alat}

Dalam perancangan suatu alat, banyak hal yang perlu di siapkan sesuai dengan kebutuhan yang akan di gunakan dalam proses pembuatan alat tersebut. Adapun alat dan komponen-komponen yang digunakan dalam pembuatan alat ini adalah:

1. Arduino UNO

adalah alat yang dipakai untuk memasukan program, yang sudah berbentuk file hexa ke dalam mikrokontroler.

2. Komputer

Digunakan untuk menulis laporan, membuat program, mendownload program.

3. Multitester

Multitester adalah alat ukur listrik yang dapat mengukur tahanan resistansi, tegangan dan kuat arus. Selain itu multitester juga bisa digunakan untuk mengetahui keadaan sebuah komponen apakah telah rusak atau tidak.

4. Bor dan Solder

Bor digunakan untuk membuat lubang pada PCB.Solder berfungsi untuk mematri kaki komponen pada PCB.

Solder biasa kita gunakan adalah solder listrik.

5. Obeng

Obeng adalah merupakan alat yang digunakan untuk mengencangkan atau mengendorkan sekrup maupun baut. Ada beberapa model obeng yang digunakan di seluruh dunia. Jenis yang sangat umum adalah (+) dan (-). Jenis obeng lain yang banyak antara lain Torx (bintang segi enam), Hex (segi enam), Robertson (kotak) dan lainnya.

6. Motor wiper

Motor wiper digunakan sebagai pengganti selenoid air atau pompa mini dengan tegangan 12 Volt dan berarus DC. Disini motor wiper yang digunakan adalah motor wiper Toyota.

\section{Bahan}

Bahan-bahan yang dibutuhkan dalam pembuatan alat.

Tabel 1 Komponen- Komponen Elektronika

\begin{tabular}{|c|l|l|}
\hline No & \multicolumn{1}{|c|}{ Nama Komponen } & \multicolumn{1}{c|}{ Jumlah } \\
\hline 1. & LCD 2x16 & 1 buah \\
\hline 2. & Mikrokontroler Arduino Uno & 1 buah \\
\hline 3. & Nozle & 2 buah \\
\hline 4. & Selang & $150 \mathrm{~cm}$ \\
\hline 5. & Motor wiper & 2 buah \\
\hline 6. & Power suplay 12 volt & 1 buah \\
\hline 7. & Moisture sensor YL-69 & 1 buah \\
\hline 8. & Relay module 5V & 1 buah \\
\hline 9. & Kabel pelangi & secukupnya \\
\hline
\end{tabular}


Berikut adalah keterangan dari komponen di atas:

1. Lcd digunakan untuk menampilkan kelembaban yang terdapat pada tanah.

2. Arduino digunakan untuk mengontrol komponen-komponen yang digunakan.

3. Nozle digunakan sebagai keran keluarnya air.

4. Selang digunakan untuk lewatnya air.

5. Motor wiper digunakan untuk memompa air yang ada

6. Power supplay digunakan sebagai sumber tegangan

7. Sensor soil moisture digunakan untuk mendeteksi kelembaban tanah yang ada pada tanaman

8. Relay module digunakan sebagai saklar on of untuk motor wiper

\section{PEMBAHASAN}

\subsection{Pengujian dan Analisa Alat}

Pengujian alat dilakukan untuk mengetahui apakah fungsi-fungsi yang telahdirencanakan bekerja dengan baik atau tidak. Pengujian alat juga berguna untuk mengetahui tingkat kinerja dari fungsi tersebut. Pengujian dilakukan pada tiap blok rangkaian sehingga apabila terjadi suatu kesalahan akan dapat diketahui secara pasti.

\subsection{Pengujian Alat}

Pada tahap ini dilakukan pengujian terhadap alat yang telah dibuat dengan cara melakukan pengambilan data terhadap beberapa parameter. Pengujian yang dilakukan antara lain meliputi:

1. Pengujian dan pengukuran rangkaian power supplay

2. Pengujian sistem kerja relay modul.

3. Pengujian komunikasi mikrokontroler arduino denganmoisture sensorYL-69

4. Pengujian rangkaian keseluruhan

\subsection{Pengujian Rangkaian Power Supllay}

Untuk simulasi awal sebelum rangkaian catu daya baik rangkaian catu daya 12 volt untuk tegangan motor DC ataupun rangkaian yang memberi suplai tegangan 5volt pada rangkaian arduino, pengujian rangkaian ini dimaksudkan untuk memberikan tegangan kepada komponen yang memiliki arus tegangan tertentu seperti catu daya 12 volt untuk memberi arus ke 2 motor DC.

Untuk mengurangi kesalahan dalam melakukan pengujian dan pengukuran pada blok rangkaian catu daya/power supply, maka perlu melakukan langkah-langkah sebagai berikut:

1. Siapkan rangkaian dan multitester.

2. Periksa terlebih dahulu rangkaian power supplay 12 volt dalam kondisi baik.

3. Hubungkan tegangan jala-jala ke rangkaian power supplay $12 \mathrm{VDC}$.

4. Siapkan multitester pada keadaan VDC untuk mengukur tegangan.

5. Lakukan kalibrasi pada alat yang digunakan untuk mengukur rangkaian sehingga didapat hasil yang akurat.

6. Hubungkan multitester pada titik uji rangkaian, kemudian catat hasilnya.

Tabel 2 Hasil pengukuran arus dan tegangan power supply

\begin{tabular}{|c|c|c|}
\hline \multicolumn{3}{|c|}{ Hasil Pengukuran Arus dan Tegangan Catu Daya } \\
\hline $\begin{array}{c}\text { Pengukur } \\
\text { an }\end{array}$ & $\begin{array}{c}\text { Power Supply } \\
12 \text { VDC }\end{array}$ & Keterangan \\
\hline \multirow{2}{*}{ Tegangan } & 0 volt & Tidak Aktif/ Standby \\
\cline { 2 - 3 } & 11,6 volt & Sistem Aktif \\
\hline \multirow{2}{*}{ Arus } & 0 Ampere & Tidak Aktif/ Standby \\
\cline { 2 - 3 } & 1 Ampere & Sistem Aktif \\
\hline
\end{tabular}

\subsection{Pengujian Rangkaian Relay Modul}


Untuk mengetahui apakah rangkaian relay modul tersebut berfungsi dengan baik, perlu di lakukan uji coba dengan cara melakukan pengecekanpin tegangan 5volt dan pin input relay modul dengan pin arduino dan sambungan antara dryer pemanas, motor pengaduk dan motor pembalik. Adapun langkah-langkah yang dilakukan dalam pengukuran pada rangkaian driver relay tersebut antara lain sebagai berikut:

1. Siapkan rangkaian driver relay module.

2. Hubungkan rangkaian driver relay modul ke pin mikrokontroler arduino uno VCC ke 5volt, GND ke GND , IN1 ke pin4, IN2 ke pin5, IN3 ke pin6, IN4 ke pin7.

3. Hubungakan relay ke motor wiper, dimana posisi penempatanya salah satu kabel di COM dan kabel selanjutnya di NO, yang diberi tegangan 220volt pada COM di relay 1.

4. Cek instalasi rangkaian relay apakah terpasang dengan baik.

5. Lakukan kalibrasi pada alat yang digunakan untuk mengukur rangkaian sehingga didapat hasil yang akurat.

6. Hubungkan multitester pada titik uji rangkaian.

7. Setelah selesai pengukuran, matikan semua peralatan yang digunakan.

Tabel 3 Hasil pengukuran arus dan tegangan relay modul

\begin{tabular}{|c|l|c|}
\hline Relay & Komponen & Tegangan \\
\hline Relay 1 & Motor wiper & 220 volt \\
& & \\
\hline
\end{tabular}

\subsection{Pengujian Rangkaian Moisture sensor YL-69}

Rangkaian Moisture sensor YL-69 berperan penting, karena moisture sensor sebagai indikator kadar air pada padi apakah padi tersebut kering atau basah, rangkaian Moisture sensor terdiri dari dua probe yang memiliki pin tegangan VCC 5volt, GND, dan pin data yang tersambung ke arduino, pastikan sambungan pada moisture sensor tersambung dengan baik antara VCC, GND dan pin data, pin data tersambung ke pin A0 pada arduino uno, ini dikarenakan data yang dikeluarkan pada sensor berupa data analog yang nilainya 1023.

Rumus perhitungan

$1024 * 100 / 1024$

Tabel 4 Hasil pengujian system

\begin{tabular}{|c|c|c|c|c|}
\hline No & $\begin{array}{c}\text { Kelembaban } \\
\text { tanah }\end{array}$ & $\begin{array}{c}\text { Presentase } \\
\text { Kadar air }\end{array}$ & Keterangan & Motor \\
\hline 1 & 290 & $29 \%$ & Kering & On \\
\hline 2 & 560 & $56 \%$ & Lembab & Of \\
\hline 3 & 540 & $54 \%$ & Lembab & Of \\
\hline 4 & 126 & $12.6 \%$ & Kering & On \\
\hline 5 & 707 & $70.7 \%$ & Basah & Of \\
\hline
\end{tabular}

Dari hasil tabel pengujian sistem diatas dapat disimpulkan:

1. Saat tanah kering sensor akan mendeteksi presentase kelembaban dan sistem akan menghidupkan motor untuk menyiram tanaman

2. Saat tanah lembab sensor akan mendeteksi presentase kelembaban tetapi sistem tidak akan menghidupkan motor/motor of

3. Saat tanah lembab sensor akan mendeteksi presentase kelembaban tetapi sistem tidak akan menghidupkan motor/motor of

4. Saat tanah kering sensor akan mendeteksi presentase kelembaban dan sistem akan menghidupkan motor untuk menyiram tanaman

5. Saat tanah kering sensor akan mendeteksi presentase kelembaban dan sistem akan menghidupkan motor untuk menyiram tanaman〉

Dari beberapa kesimpulan diatas. Sistem ini sudah dapat berjalan sesuai yang diinginkan oleh penulis. 


\subsection{Pengujian Sistem Rangkaian Keseluruhan}

Untuk mengurangi kesalahan dalam melakukan pengujian maka terlebih dahulu diimplementasikan pada perangkat[10]. Rangkaian arduino menggunakan powersupply 12volt untuk menghasilkan keluaran tegangan $12 \mathrm{volt}$ yang terhubung dengan mikrokontroler arduino sebagai catu daya. Sedangkan LCD tegangan output menggunakan power supply 5volt yang diregulasi menggunakan IC 7805 untuk menghasilkan keluaran tegangan 5volt yang terhubung dengan mikrokontroler arduino sebagai catu daya, sementara motor wiper menggunakan tegangan 220Volt. Sistem ini dirancang menggunakan mikrokontroler Arduino, Moisture Sensor YL-69, dan relay modul 5volt sebagai sumber alat pengendali. Relay modul 5volt digunakan untuk mengontrol tegangan yang diberikan power supply 12 volt.

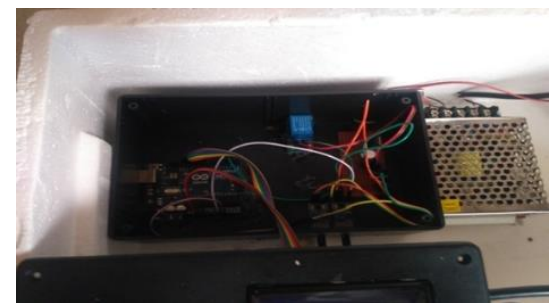

Gambar 3 Tampak dalam Alat keseluruhan

Cara kerja dari alat penyiramtanaman otomatis Berbasis Arduino Dengan motor wiper Sebagai pengganti pompa airadalah sensor soil moisture sensor YL 69 diproses oleh mikrokontroller, dimana soilmoisture sensor YL-69 menentukan tingkat kelembaban tanah ada 3 kondisi yang persentase yang ditentukan pada moisture sensor YL-69 yaitu lembab, basah, kering. Bila moisture sensor YL-69 mendeteksi tanah kering yaitu rentang 0 sampai 300driver relay yang disambung ke motor wiper yang diberi tegangan 220 volt .



Gambar 4 skema rangkaian keseluruhan

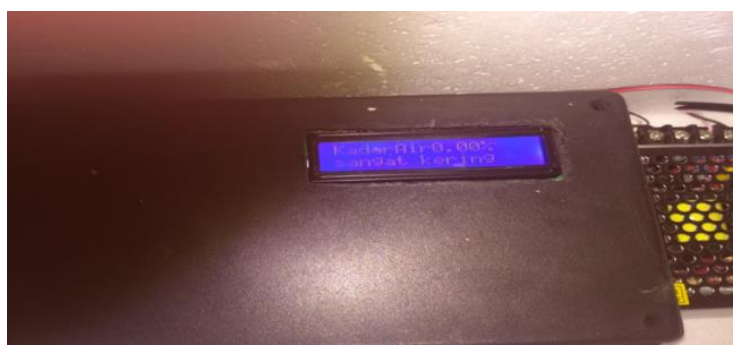

Gambar 5 Tampilan LCD 


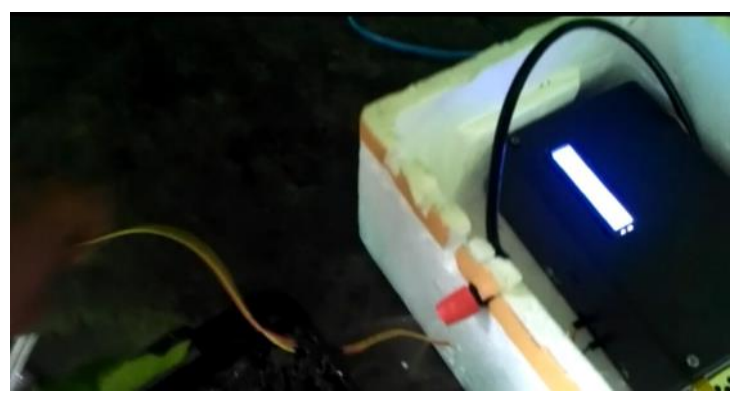

Gambar 6 Tampilan Alat Saat Bekerja

\section{KESIMPULAN}

\subsection{Kesimpulan}

Setelah dilakukan pengujian terhadap alat, dapat diambil kesimpulan diantaranya adalah :

Dari hasil pengujian sistem, ketika tanah kering atau kadar air 0-49\% maka sistem akan hidup atau on, Dan ada saat tanah lembab atau kadar air 50-69\% maka sistem akan of. Ketika tanah lembab atau basah maka sistem tidak akan hidup. Kelemahan. Sebagai akhir dari laporan ini ada beberapa saran yang dapat penulis sampaikan yaitu:

1. Untuk kedepannya sebaiknya ditambahkan modul GSM agar saat sistem hidup, mati, atau mengalami eror kita akan mengetahui pemberitahuan melalui sms pada smartphone

2. Disarankan untuk menggunakan sensor soil moisture yang sudah diupgrade.

3. Sebaiknya menambahkan sensor pendeteksi ph tanah

\section{DAFTAR PUSTAKA}

[1] E. Nasrullah, A. Trisanto, and L. Utami, "Rancang Bangun Sistem Penyiraman Tanaman Secara Otomatis Menggunakan Sensor Suhu LM35 Berbasis Mikrokontroler ATMega8535," J. Rekayasa dan Teknol. Elektro, vol. 5, no. 3, pp. 182-192, 2011.

[2] B. Santoso and A. D. Arfianto, "Sistem Pengganti Air Berdasarkan Kekeruhan Danpemberi Pakan Ikan Pada Akuarium Air Tawar Secara Otomatis Berbasis Mikrokontroler ATMEGA 16," J. Ilm. Teknol. Inf. Asia, vol. 8, no. 2, pp. 33-48, 2014.

[3] S. Samsugi and D. E. Silaban, "Purwarupa Controlling Box Pembersih Wortel Dengan Mikrokontroler," vol. 2018, no. November, pp. 166-172, 2018.

[4] C. Arif, B. I. Setiawan, and M. Mizoguchi, "Penentuan Kelembaban Tanah Optimum Untuk Budidaya Padi Sawah SRI (System Of Rice Intensification) Menggunakan Algoritma Genetika,” J. Irig., vol. 9, no. 1, p. 29, 2014, doi: 10.31028/ji.v9.i1.29-40.

[5] H. Karamina, W. Fikrinda, and A. T. Murti, "Kompleksitas pengaruh temperatur dan kelembaban tanah terhadap nilai $\mathrm{pH}$ tanah di perkebunan jambu biji varietas kristal (Psidium guajava 1.) Bumiaji, Kota Batu," Kultivasi, vol. 16, no. 3, pp. 430-434, 2018, doi: 10.24198/kultivasi.v16i3.13225.

[6] S. Samsugi and A. Suwantoro, "Pemanfaatan Peltier dan Heater Sebagai Alat Pengontrol Suhu Air Pada Bak Penetasan Telur Ikan Gurame,” Conf. Inf. Technol., pp. 295-299, 2018.

[7] M. S. Prof. Dr. Ir. H. Sarwono Hardjowigeno, Ilmu Tanah. Jakarta: Akademika Pressindo, 2007.

[8] H. Tugiyono, Bertanam tomat. Jakarta: Niaga Swadaya, 1999.

[9] Melwin Syafrizal Daulay, Mengenal Hardware-Software dan Pengelolaan Instalasi Komputer. Yogyakarta: Andi Offset, 2007.

[10] K. Pindrayana, R. Indra Borman, B. Prasetyo, and S. Samsugi, "Prototipe Pemandu Parkir Mobil Dengan Output Suara Manusia Mengunakan Mikrokontroler Arduino Uno,” CIRCUIT J. Ilm. Pendidik. Tek. Elektro, vol. 2, no. 2, pp. 71-82, 2018, doi: 10.22373/crc.v2i2.3705. 